\title{
The Tumor Infiltrating Lymphocytes (TILs): Did We Find the Missed Piece of the Huge Puzzle?
}

\author{
Suzan Samir Elsharkawy*, Mohamed Abd Elrheem, Samia Abd Elrheem \\ Department of Obstetrics and Gynecology, Faculty of Medicine, Alexandria University, Alexandria, Egypt \\ Email: *s_abdelrahim00@alexmed.edu.eg
}

How to cite this paper: Elsharkawy, S.S., Elrheem, M.A. and Elrheem, S.A. (2021) The Tumor Infiltrating Lymphocytes (TILs): Did We Find the Missed Piece of the Huge Puzzle? Open Journal of Obstetrics and Gynecology, 11, 146-161.

https://doi.org/10.4236/ojog.2021.112017

Received: December 21, 2020

Accepted: February 22, 2021

Published: February 25, 2021

Copyright $\odot 2021$ by author(s) and Scientific Research Publishing Inc. This work is licensed under the Creative Commons Attribution International License (CC BY 4.0).

http://creativecommons.org/licenses/by/4.0/

\begin{abstract}
Tumor infiltrating lymphocytes (TILs) are used in evaluating the prognosis and determining treatment of different types of cancer with variable degrees of success. The usage of checkpoint inhibitor immunotherapy as a treatment variety for cancer and Adoptive cell therapy is associated with many complications, severe side effects and high expenses. Recently, in a limited number of metastatic GIT and breast cancers, the identification of T-cell specific against so-called tumor neo-antigens and Adoptive transfer of those lymphocytes resulted in some improvement. In 2020, Detection of a T cell receptor (TCR) in a $\mathrm{T}$ cell clone that recognized and killed most human cancer cell lines in vitro via the monomorphic MHC class I-related protein MR1, offers an opportunity for pan-cancer therapy Twenty three years earlier, Moist Heat was used successfully to activate a whole different and new immune response that was able to detect genetic mutation in the affected cancer cells and cured many cases of squamous and basal cell carcinomas. In this commentary review, we aimed to revise the literature for updates of TILs usage in cancer prognosis and treatment.
\end{abstract}

\section{Keywords}

Tumor Infiltrating Lymphocytes, Cancer, Checkpoint Inhibitor,

Adoptive Cell Therapy, T Cell Receptor (TCR), Moist Heat,

Pan-Cancer Therapy, Squamous Cell Carcinoma, Basal Cell Carcinomas

\section{Introduction}

Tumor infiltrating lymphocytes (TILs) are a group of lymphocytes that surround tumor cells and exhibit diverse functions in various subsets. TILs have been identified in primary tumors, lymph nodes, and metastases. As a heterogeneous group, TILs include: dendritic cells (DCs), natural killer (NK) cells, myelo- 
id-derived suppressor cells (MDSCs), macrophages, and most importantly $\mathrm{T}$ cells [1]. CD3+, CD4+, CD8+ and FoxP3+ T lymphocytes are the most common subsets of TILs. CD8+ T lymphocytes belong primarily to cytotoxic T lymphocytes (CTLs), which are primarily responsible for the elimination of target cells, including tumor cells. CD4+ T lymphocytes are referred to as $\mathrm{T}$ helper lymphocytes (Ths) [2]. Mosmann et al. [3] first divided CD4+ T lymphocytes into Th1 and Th2 cells in the early 1980s based on different cell functions and cytokines secreted. Th1 cells activate the toxic effects of killer cells, such as enhancing CTLs, or stimulate a delayed-type hypersensitivity to mediate cellular immune response. Th2 cells promote antibody production and mediate the humoral immune response. Multiple Researches also confirmed that other subgroups exist in CD4+ T lymphocytes, such as CD4+ regulatory T lymphocytes (Tregs), which characteristically express Forkhead box P3 (Foxp3). Tregs are the most important immunosuppressive cells in the body [4] [5]. The value of TILs in oncology is not hard to imagine based on the importance of these cells in tumor immunity, and immune cells, especially TILs, have been a hotspot in cancer research. TILs may present a key breakthrough for anti-tumor therapy.

Our increasing knowledge of the immune cellular response, especially tumor-infiltrating lymphocytes, supports the important value of these cells in many malignant tumors. Some studies assessed the prognostic value of tumor-infiltrating lymphocytes in various types of tumors, such as breast cancer, gastric cancer, non-small cell lung cancer, and ovarian cancer [6] [7] [8] [9], others assigned their importance as a treatment of primary tumors or metastasis in the form of immunologic therapy [10]. Our commentary review aimed to search the literature for the different implications of TILs in the prognosis and treatment of various types of cancer.

\section{TILs for Tumor Prognosis}

Many studies across a wide range of human cancers have shown a definite association between the existence of tumor infiltrating lymphocytes (TIL) and patient survival [11] [12] [13] [14]. To further understand this phenomenon, additional immune markers have been used to subdivide $\mathrm{CD} 3 \mathrm{~T}$ cells into functional groups, with special emphasis on cytotoxic (e.g., CD8) and regulatory (e.g., CD4, CD25, FoxP3) phenotypes [15]. While TIL-expressing cytotoxic markers are generally correlated to favorable prognosis, TIL-expressing regulatory markers (Tregs) were initially reported to associate with poor prognosis [15]. This finding fit with the general note that Tregs suppress the adaptive immune responses and led many groups to start mechanisms to deplete Tregs from patients with cancer as a means to enhance tumor immunity [16] [17] [18].

Bates et al. [19] noticed that Treg numbers were significantly higher in breast carcinomas than in the normal breast tissue and more interestingly higher in invasive tumors than in cases of in-situ ductal carcinoma. Furthermore, a bigger numbers of infiltrating FOXP3+ lymphocytes were correlated with higher grade, 
positive lymph node, and poor survival outcomes in invasive Breast Cancer patients. In addition, Liu et al. [20] found that FOXP3+ Tregs infiltrated the surrounding stroma more than the central tumor, and the presence of FOXP3+ Tregs in the adjacent stroma indicated chemo-sensitive tumors. Controversies exist on how these cells present in tumor. The most acceptable hypothesis is that tumor can recruit immunosuppressive inflammatory cells to intra-tumoral or adjacent stromal sites, those different immune cells recruited have different roles in various cancers [21].

As the most specific Treg marker, FOXP3 expression has been shown to correlate with a poor prognosis in various types of human cancer, including breast cancer and gastrointestinal cancers [22] [23]. However, a better prognostic value of Tregs has also been observed in head and neck squamous cell carcinoma [24]. For melanoma, most previous studies have suggested that FOXP3+ cells are associated with a favorable prognosis [25]; inconsistently, the controversial results have also been observed by others [26] [27]. Generally, the infiltration of Treg cells into tumors inhibits antitumor immune responses, and the depletion of Treg cells enhances anticancer treatments [28].

The mechanisms by which immune cells can predict prognosis are not clear. Various types of immune cells play different roles in the tumor microenvironment, primarily via immunosuppressive and immunological effects. Some cells exert immunosuppressive effects, such as Foxp3+ Treg cells and mastocytes, and other cells exert immunological effects, such as cytotoxic T lymphocytes (CTLs), memory $\mathrm{T}$ lymphocytes, macrophages, and $\mathrm{T}$ helper lymphocytes. These effects are indispensable and influence each other. The determining factor of overall immune status depends on the sum of their effector functions or secretion of immuno-active substances.

Immunological effector cells can be inhibited via the secretion of immunosuppressive factors, such as IL-10 and TGF- $\beta 1$, or competitive binding with IL-2 by immunosuppressive cells. These conditions promote the generation of immune tolerance [29] [30]. These immune conditions hamper the anti-tumor immune response, which is more favorable for tumor growth and metastasis.

\section{TILs for Tumor Immune Therapy}

The immune system plays a vital protective role against cancer by identifying and eliminating tumor cells [31]. Cancer cells express a variety of tumor associated antigens (TAA) which can be recognized inducing an immune response against cancer [32]. However, the immune system cannot always recognize the specific target or the response might not be strong enough to destroy the cancer. Sometimes cancer cells take advantage of the ability to hide from the immune system by exploiting a series of immune escape mechanisms that might be responsible for the failure of the immune system to destroy or control cancer [33]. Immunotherapy may be viewed as a promising approach to anticancer treatment which has been reported to overcome tumor-induced immune dysfunction 
and restore the ability of the immune system to fight cancer [34].

Genetic aberrations underpin all cancers. These genetic alterations are specific to cancers and are not present in normal tissues; thus, treatments that specifically target the protein product of these genetic alterations may provide clinical benefit in the absence of normal tissue toxicities. Cancer immunotherapies such as adoptive cell therapy with tumor-infiltrating lymphocytes (TILs) or immune checkpoint inhibitors have demonstrated clinical activity in patients with metastatic melanoma, smoking-induced lung cancer, renal cell carcinomas, and cancers with DNA mismatch repair deficiency [35]-[41]. Accumulating evidences suggest that some of these clinical responses are most likely mediated by $\mathrm{T}$ cells that target the somatic mutations expressed by the tumor cells [41]-[48]. However, immune checkpoint blockade therapies are still ineffective against vast majority of metastatic gastrointestinal (GI) cancers [36] [41], which have less number of mutations when compared with those of melanoma and smoking induced lung cancers [41] [49] [50]. This suggests that mutation-reactive T cells may be rare or absent in the majority of these patients. If so, this would likely pose major challenges for the development of immunotherapies that target mutations in many patients with GI cancers.

Tumour-specific neoantigens arise from mutations that accumulate in tumours over time, and have been demonstrated to elicit $\mathrm{T}$ cell responses within the patient. These neoantigens are thought to be the major contributors to the clinically relevant responses that have been documented following treatment with immune-therapeutic approaches [51]. Tumours with the highest mutational burden present more tumour neoantigens to the host and appear to be more susceptible to immunotherapy [52]. More Recent data suggest that earliest clonal mutations which arise from the first transforming mutagenic events are kept in all the subclones despite the acquisition of more and more mutations during the natural history of the tumour progression due to evolutionary or therapeutic selection pressures [53]. Thus, the first clonal mutations are present in all cancer cells of a patient, while other subsequent subclonal mutations are present in only a specific proportion of the cancer cells. According to that, a T cells targeting a single clonal neoantigen is expected to lead to complete tumour regression if all of the cells express the antigen targeted.

A therapeutic approach of identifying clonal neoantigens, priming TILs ex vivo to recognize them and treating patients with their own expanded clonal neoantigen-reactive $\mathrm{T}$ cell $(\mathrm{cNeT})$ product is expected to effectively increase the ability of the immune system to eliminate all of the tumour cells in the body, and solve the problem of intratumoural heterogeneity, as the recognized clonal neoantigens are present in all tumour cells and are the most relevant therapeutic targets for $\mathrm{T}$ cells.

\section{Immune Checkpoint Inhibitors Therapy}

Immune checkpoints are the $\mathrm{T}$ lymphocytes activation modulators that are es- 
sential for maintaining self-tolerance and modifying the duration and degree of physiological immune responses in peripheral tissues in order to stop uncontrolled immune reactions and self-tissue damage. Unfortunately, cancer cells are able to escape from the immune system mainly by overcoming the immune cell-intrinsic checkpoints that induce the tumor cells to avoid the host immune system by inhibiting $\mathrm{T}$ lymphocytes activation [54]. Blocking of these immune checkpoints can modulate the immunosuppressive environment, augment anti-tumor immunity and induce tumor regression. Blockers may be cytotoxic T-lymphocyte antigen 4 (CTLA-4), programmed death 1 (PD-1), PD ligand 1 (PD-L1) and lymphocyte activation gene-3 (LAG-3) with monoclonal antibodies (mAbs) [55].

Inhibition of CTLA-4 by ipilimumab represents the first drug ever used in immune checkpoint inhibitor treatment. Ipilimumab was licensed for use in advanced metastatic melanoma [37]. The second group of drugs for immune checkpoint inhibition were anti PD-1 (nivolumab and pembrolizumab) or anti PD-L1 (atezolizumab, avelumab and durvalumab) antibodies which are currently registered by the U.S. Food and Drug Administration (FDA) for metastatic malignant melanoma, non-small cell lung cancer (NSCLC), renal cell cancer (RCC), head and neck cancer (HNSC), urothelial carcinoma and Hodgkin's lymphoma in various stages of the respective disease and in the context of varying treatment histories [56]-[62]. Many other malignancies (e.g. hepatocellular carcinoma, cervical cancer [63], ovarian cancer, mesothelioma, gastric cancer, B-cell non-Hodgkin lymphoma) are currently under clinical investigation to determine a possible efficacy of checkpoint inhibition [64] [65] [66].

However, the development of checkpoint inhibitor immunotherapy as a treatment variety for cancer has been complicated by several issues such as eligibility of the participants in clinical trial, the methods of assessment, financial support, the selection of the best dose and schedule, and the side effects of the immunotherapeutic agents [67]. The use of checkpoint inhibitors may induce frequent drug-related adverse events that have a wide range of severity. This includes diarrhea, rash, fatigue, nausea, pruritus, headache, pneumonitis, hypothyroidism, vitiligo, colitis, hepatitis, hypophysitis, sarcoidosis, endophthalmitis, diabetes mellitus, liver dysfunction and myasthenia gravis [68].

\section{Adoptive Cell Therapy}

Another promising form of immunotherapy is adoptive cell therapy (ACT) using the infusion of autologous tumor-infiltrating lymphocytes (TIL) expanded ex vivo combined with high-dose (HD) interleukin (IL-2) therapy [69] [70]. ACT involves the isolation of viable tumor tissue and the expansion of TIL with IL-2 over 4 to 5 weeks from tumor fragments placed in culture [71]. The TILs are then further let to expand in a bigger scale using anti-CD3 activation and exogenous IL-2 in the presence of autologous or allogeneic-irradiated feeder cells [71]. This protocol is known as the "rapid expansion protocol" (REP) and can 
produce as much as 100 to 150 billion cells ready for infusion [71]. Longer responses to TIL therapy have been achieved by adding a preparative lymphodepleting regimen using a combination of cyclophosphamide and fludarabine [72] [73], which lead to an increase in the persistence of the transferred cells [74].

Adoptive cell transfer therapy has shown impressive results in patients with metastatic melanoma. Objective response rates of $40 \%-50 \%$ including complete tumor regression in $10 \%-20 \%$ of treated patients have consistently been reported [35] [75] [76] [77]. The major advantage of TIL-ACT over the standard treatment regimens is the relative high frequency and long-term durability of complete responses.

In a sample of women with advanced or recurrent ovarian cancer, a pilot trial was performed using adoptive transfer of ex vivo IL-2 expanded TILs following a single dose of intravenous cyclophosphamide resulted in good response rates. Out Of the 7 patients treated with adoptive transfer of TILs alone, 1 achieved a complete response and 4 achieved partial responses [78].

TIL-ACT has never been established as a standard treatment; only few centers around the world have applied TIL-ACT and mostly as a salvage treatment after failure of standard therapies. The complexity of TIL production and severe treatment-associated toxicity are obvious boundaries for a more widespread application. The preparative lymphodepleting chemotherapy contributes markedly to treatment-related toxicity but is necessary for achievement of durable clinical responses [79]-[84]. Previous studies showed that high durability of the infused cells was achieved only after preparation of the patients by lymphodepletion prior to TIL transfer. Most toxicities resulting from current ACT regimens are related to HD IL2 administered after cell transfer. Interleukin 2 is essentially administered to support in vivo proliferation and persistence of the infused cells.

\section{Immune Recognition of Somatic Mutations in Cancer Cells}

Immunotherapy using either checkpoint blockade or the adoptive transfer of antitumor lymphocytes has shown effectiveness in treating cancers with high levels of somatic mutations-such as melanoma, smoking-induced lung cancers and bladder cancer with minor effect in epithelial cancers that have lower somatic mutation rates, such as gastrointestinal tract, breast and ovarian cancers.

Recent technological improvements have fastened the identification of T-cell that specific against so-called tumor neo-antigens, resulting from nonsynonymous somatic tumor mutations, and have shown their successful application in immune-mediated rejection of melanoma, lung cancer, leukemia, and gastrointestinal cancers [47] [85]-[90].

Adoptive transfer of autologous lymphocytes that selectively target proteins encoded by somatically modified genes has mediated some objective clinical regressions in patients with metastatic bile duct, colon and breast cancers. In cholangiocarcinoma, Tran E et al. (2014) demonstrated that tumor-infiltrating lymphocytes (TIL) from a patient with metastatic tumor contained CD4+ T hel- 
per 1 (TH1) cells recognizing a mutation in erbb2 interacting protein (ERBB2IP) expressed by the cancer. After adoptive transfer of that mutation-specific poly-functional TIL, the patient achieved a decrease in target lesions with prolonged stabilization of disease [88].

In the next year (2015) they demonstrated tumor-infiltrating lymphocytes (TILs) from 9 out of 10 patients with metastatic gastrointestinal cancers that contained $\mathrm{CD} 4(+)$ and/or $\mathrm{CD} 8(+) \mathrm{T}$ cells which were able to recognize one to three neo-epitopes derived from somatic mutations expressed by the patient's own tumor [89]. Rosenberg SA et al., (2018) described a case with chemorefractory hormone receptor (HR)-positive metastatic breast cancer. This case was treated using tumor-infiltrating lymphocytes (TILs) reactive against mutant types of four proteins-SLC3A2, KIAA0368, CADPS2 and CTSB. Adoptive transfer of these mutant-protein-specific TILs in conjunction with interleukin (IL)-2 and checkpoint blockade resulted in a complete durable regression of metastatic breast cancer [90].

In 2020, Andrew Sewell et al., using genome-wide CRISPR-Cas9 screening, found that a T cell receptor (TCR) in a MC.7.G5 clone recognized and killed most human cancer cell lines in vitro via the monomorphic MHC class I-related protein MR1. More than $95 \%$ of each cancer cell line from lung, cervix, melanomas, blood and kidney were killed while remaining inert to noncancerous healthy cells. A clone MC.7.G5-TCR lenti-viral transduced to T cells of stage IV cancer patients, enabled killing of autologous and non-autologous melanomas in vitro. In NSG mice; An MR1-restricted T cell clone, mediated in vivo regression of leukemia and enhanced the survival. They suggested that recognition occurred via sensing of the cancer metabolome but were unable to detect it. Their findings offered opportunities for HLA-independent pan-cancer immunotherapy [91].

\section{Can We Selectively Activate Neo-Epitope Specific CD4+/CD8+ T Cells in Vivo? Moist Heat Is the Correct Answer}

According to literature, Moist heat $(\mathrm{MH})$ was mentioned for the first time as a cancer therapy in 1997 [92], but the use of moist heat started four years earlier. When Dr. Mohamed Samir Abdel-rheem treated a resistant case of Tenia corporis by applying boiling water directly on some of the skin lesions, he planned to destroy the infected epidermis with it. Surprisingly, all the infected areas of the skin were cured, even those areas he didn't treat. Such a strange result raised his suspicions about a new type of immune reaction that might be stimulated with the aid of moist heat and attacked the whole infected areas. Encouraged by his thoughts, Abdel-rheem used MH to treat fifteen cases of Rodent ulcers (basal cell carcinoma), three cases of squamous cell carcinoma and one case of Mycosis Fungoidis (skin T-cell lymphoma). Biopsies were taken before and after application of moist heat and sent for histopathology to confirm the diagnosis and fol- 
low up the healing process. All cases were clinically free after 20 to 30 days and didn't have any cancer recurrence for 18 months of follow up. Abdel-rheem published his work in Alexandria Journal of veterinary Science (AJVS) 1997, on his website (http://moistheat.megs.com) 2005, and as a talk in the first annual world summit of antivirals conference held in Kunming China 2008.

Observing the effects of moist heat on different types of pathologies (three cutaneous cancers, cutaneous viral warts and some autoimmune diseases), Abdel-rheem occluded that MH simply activated a new immune response that was target specific, and by examining the sequential healing biopsies he noticed a massive lymphocyte infiltration of the tumor site (Photo 1), which was Synchronous with reactive leukocytosis in peripheral blood films [92]. All those different diseases shared one feature; abnormal changes occurring in some genes inside the nucleus. This fact led him to suggest a new immunity reaction, in which there is a specific lymphocyte that is able to recognize changes in genes inside the nuclei of diseased cells then gather around them in an Inactive form. Upon Exposure to moist heat, this lymphocyte got activated, multiplies and selectively destroys the abnormal gene harboring cells but not damaging the surrounding normal noncancerous cells. This occurred in cancer, viral warts or auto-immune diseases. By that he was able to explain the similarity of reaction and disease regression in all those diverse pathologies.

Abdel-rheem called this mysterious cell "hot water cell or Samir S cell" and the novel immune reaction as "Samir reaction". He wrote: "We can say that we have 2 types of immune reactions; one recognizes changes in surface markers of cell membrane and reacts by $\mathrm{B}$ and $\mathrm{T}$ lymphocytes, and the other system recognizes changes in genes and reacts by $\mathrm{S}$ cells when activated by moist heat" [44].

When we compare the work of the last two groups of scientists; Andrew Sewell et al, and Abdel-rheem, we will find almost the exact words that described the same cell; a $\mathrm{T}$ cell that is able to recognize genetic changes in cancer cells, killing them without harming healthy tissues. Sewell called it "MC.7.G5 T cell clone" in 2020 and Abdel-rheem called it "Samir cell" in 1997, adding his brilliant method to activate it in vivo via $\mathrm{MH}$ [92].
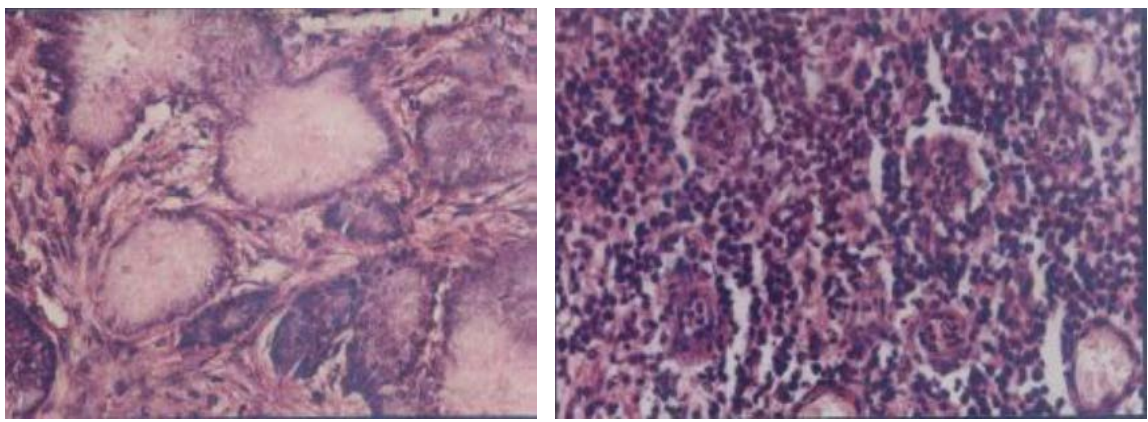

Photo 1. (Left) Microscopic picture to squamous cell carcinoma (SCC) showing malignant cell nests with scanty lymphocytes before moist heat $(\mathrm{MH})$ therapy; (Right) microscopic picture showing numerous lymphocytes surrounding few malignant cells after $\mathrm{MH}$ use [44] [92]. 
The use of TILs for treatment of cancer was always restricted for terminal non responsive cases as salvage treatment. This may be the chief reason for its unsatisfactory results. Furthermore, the complexity of its protocols, the high cost and toxic effects hinder its progression. If we have a simple cheap effective and safe method to activate those marvelous cells with moist heat, let us treat our patients.

\section{Conclusions}

Tumor infiltrating lymphocytes can be used in the prognosis and treatment of different cancer types in variable degrees. The usage of checkpoint inhibitors and Adoptive cell immunotherapy as a treatment variety for cancer is associated with many complications, severe side effects and high expenses. Last year, Andrew Sewell described a $\mathrm{T}$ cell receptor (TCR) that interacts with a molecule called MR1, which is present on the surface of every cell in human body and thought to "flag" the distorted metabolism inside a cancer cell to the immune system. Twenty three years earlier, Moist Heat was used successfully to activate a whole different and new immune response that was able to detect genetic mutation in the affected cancer cells and cured many cases of squamous and basal cell carcinomas. While performing his simple research, Abdel-rheem discovered a unique way to awaken the sleeping monster (the TCR cells or Samir cells) and gave us the missed piece of our huge puzzle.

We need to perform more researches in this area to detect, isolate, study, and activate Samir cells. We are in great need for well-designed controlled clinical trial to properly evaluate $\mathrm{MH}$ as a method for pan-cancer therapy. Maybe the day will come and we will be able enough to unleash the beast: "The Tumer Infiltrating Lymphocytes".

\section{Conflicts of Interest}

The authors declare no conflicts of interest regarding the publication of this paper.

\section{References}

[1] Candido, J. and Hagemann, T. (2013) Cancer-Related Inflammation. Journal of Clinical Immunology, 33, 79-84. https://doi.org/10.1007/s10875-012-9847-0

[2] Nishimura, T., Iwakabe, K., Sekimoto, M., Ohmi, Y., Yahata, T., Nakui, M., Sato, T., Habu, S., Tashiro, H., Sato, M., et al. (1999) Distinct Role of Antigen-Specific T Helper Type 1 (Th1) and Th2 Cells in Tumor Eradication in Vivo. Journal of Experimental Medicine, 190, 617-628. https://doi.org/10.1084/jem.190.5.617

[3] Mosmann, T.R., Cherwinski, H., Bond, M.W., Giedlin, M.A. and Coffman, R.L. (1986) Two Types of Murine Helper T Cell Clone. I. Definition According to Profiles of Lymphokine Activities and Secreted Proteins. Journal of Immunology, 136, 2348-2357.

[4] Liston, A. and Gray, D.H. (2014) Homeostatic Control of Regulatory T Cell Diversity. Nature Reviews Immunology, 14, 154-165. https://doi.org/10.1038/nri3605 
[5] Sakaguchi, S., Miyara, M., Costantino, C.M. and Hafler, D.A. (2010) FOXP3 ${ }^{+}$Regulatory $\mathrm{T}$ Cells in the Human Immune System. Nature Reviews Immunology, 10, 490-500. https://doi.org/10.1038/nri2785

[6] Dushyanthen, S., et al. (2015) Relevance of Tumor-Infiltrating Lymphocytes in Breast Cancer. BMC Medicine, 13, 202. https://doi.org/10.1186/s12916-015-0431-3

[7] Kang, B.W., et al. (2016) Prognostic Value of Tumor-Infiltrating Lymphocytes in Epstein-Barr Virus-Associated Gastric Cancer. Annals of Oncology, 27, 494-501. https://doi.org/10.1093/annonc/mdv610

[8] Schalper, K.A., et al. (2015) Objective Measurement and Clinical signiFicance of TILs in Non-Small Cell Lung Cancer. Journal of the National Cancer Institute, 107, dju435. https://doi.org/10.1093/jnci/dju435

[9] Santoiemma, P.P. and Powell, D.J. (2015) Tumor Infiltrating Lymphocytes in Ovarian Cancer. Cancer Biology \& Therapy, 16, 807-820. https://doi.org/10.1080/15384047.2015.1040960

[10] Rosenberg, S.A., Yannelli, J.R., Yang, J.C., Topalian, S.L., Schwartzentruber, D.J., Weber, J.S., Parkinson, D.R., Seipp, C.A., Einhorn, J.H. and White, D.E. (1994) Treatment of Patients with Metastatic Melanoma with Autologous Tumor-Infiltrating Lymphocytes and Interleukin 2. Journal of the National Cancer Institute, 86, 1159-1166. https://doi.org/10.1093/jnci/86.15.1159

[11] Galon, J., et al. (2006) Type, Density, and Location of Immune Cells within Human Colorectal Tumors Predict Clinical Outcome. Science, 313, 1960-1964.

https://doi.org/10.1126/science.1129139

[12] Leffers, N., Gooden, M.J., de Jong, R.A., Hoogeboom, B.N., ten Hoor, K.A., Hollema, H., et al. (2009) Prognostic Significance of Tumor-Infiltrating T-Lymphocytes in Primary and Metastatic Lesions of Advanced Stage Ovarian Cancer. Cancer Immunology, Immunotherapy, 58, 449-459. https://doi.org/10.1007/s00262-008-0583-5

[13] Sato, E., Olson, S.H., Ahn, J., Bundy, B., Nishikawa, H., Qian, F., et al. (2005) Intraepithelial CD8 Tumor-Infiltrating Lymphocytes and a High CD8/Regulatory T Cell Ratio Are Associated with Favorable Prognosis in Ovarian Cancer. Proceedings of the National Academy of Sciences of the United States of America, 102, 18538-18543. https://doi.org/10.1073/pnas.0509182102

[14] Zhang, Y.L., Li, J., Mo, H.Y., Qiu, F., Zheng, L.M., Qian, C.N., et al. (2010) Different Subsets of Tumor Infiltrating Lymphocytes Correlate with NPC Progression in Different Ways. Molecular Cancer, 9, Article No. 4. https://doi.org/10.1186/1476-4598-9-4

[15] Curiel, T.J., Coukos, G., Zou, L., Alvarez, X., Cheng, P., Mottram, P., et al. (2004) Specific Recruitment of Regulatory $\mathrm{T}$ Cells in Ovarian Carcinoma Fosters Immune Privilege and Predicts Reduced Survival. Nature Medicine, 10, 942-949. https://doi.org/10.1038/nm1093

[16] Barnett, B., Kryczek, I., Cheng, P., Zou, W. and Curiel, T.J. (2005) Regulatory T Cells in Ovarian Cancer: Biology and Therapeutic Potential. American Journal of Reproductive Immunology, 54, 369-377. https://doi.org/10.1111/j.1600-0897.2005.00330.x

[17] Morse, M.A., Hobeika, A.C., Osada, T., Serra, D., Niedzwiecki, D., Lyerly, H.K., et al. (2008) Depletion of Human Regulatory T Cells Specifically Enhances Antigen-Specific Immune Responses to Cancer Vaccines. Blood, 112, 610-618. https://doi.org/10.1182/blood-2008-01-135319

[18] Powell Jr., D.J., Attia, P., Ghetie, V., Schindler, J., Vitetta, E.S. and Rosenberg, S.A. 
(2008) Partial Reduction of Human FOXP3 CD4 T Cells in Vivo after CD25-Directed Recombinant Immunotoxin Administration. Journal of Immunotherapy, 31, 189-198. https://doi.org/10.1097/CJI.0b013e31815dc0e8

[19] Bates, G.J., Fox, S.B., Han, C., Leek, R.D., Garcia, J.F., Harris, A.L., et al. (2006) Quantification of Regulatory T Cells Enables the Identification of High-Risk Breast Cancer Patients and Those at Risk of Late Relapse. Journal of Clinical Oncology, 24, 5373-5380. https://doi.org/10.1200/JCO.2006.05.9584

[20] Liu, F., Lang, R., Zhao, J., Zhang, X., Pringle, G.A., Fan, Y., et al. (2011) CD8(+) Cytotoxic $\mathrm{T}$ Cell and FOXP3 ${ }^{+}$Regulatory $\mathrm{T}$ Cell Infiltration in Relation to Breast Cancer Survival and Molecular Subtypes. Breast Cancer Research and Treatment, 130, 645-655. https://doi.org/10.1007/s10549-011-1647-3

[21] Andre, F., Dieci, M.V., Dubsky, P., Sotiriou, C., Curigliano, G., Denkert, C., et al. (2013) Molecular Pathways: Involvement of Immune Pathways in the Therapeutic Response and Outcome in Breast Cancer. Clinical Cancer Research, 19, 28-33. https://doi.org/10.1158/1078-0432.CCR-11-2701

[22] Takenaka, M., Seki, N., Toh, U., Hattori, S., Kawahara, A., Yamaguchi, T., Koura, K., Takahashi, R., Otsuka, H., Takahashi, H., et al. (2013) FOXP3 Expression in Tumor Cells and Tumor-Infiltrating Lymphocytes Is Associated with Breast Cancer Prognosis. Molecular and Clinical Oncology, 1, 625-632.

https://doi.org/10.3892/mco.2013.107

[23] Shang, B., Liu, Y., Jiang, S.J. and Liu, Y. (2015) Prognostic Value of Tumor-Infiltrating FoxP3 ${ }^{+}$Regulatory T Cells in Cancers: A Systematic Review and Meta-Analysis. Scientific Reports, 5, Article No. 15179. https://doi.org/10.1038/srep15179

[24] de Ruiter, E.J., Ooft, M.L., Devriese, L.A. and Willems, S.M. (2017) The Prognostic Role of Tumor Infiltrating T-Lymphocytes in Squamous Cell Carcinoma of the Head and Neck: A Systematic Review and Meta-Analysis. Oncoimmunology, 6, e1356148. https://doi.org/10.1080/2162402X.2017.1356148

[25] Knol AC, Nguyen JM, Quereux G, Brocard A, Khammari A, Dreno B. (2011) Prognostic Value of Tumor-Infiltrating Foxp3+ T-Cell Subpopulations in Metastatic Melanoma. Experimental Dermatology, 20, 430-434. https://doi.org/10.1111/j.1600-0625.2011.01260.x

[26] Lagouros, E., Salomao, D., Thorland, E., Hodge, D.O., Vile, R. and Pulido, J.S. (2009) Infiltrative T Regulatory Cells in Enucleated Uveal Melanomas. Transactions of the American Ophthalmological Society, 107, 223-228.

[27] Mougiakakos, D., Johansson, C.C., Trocme, E., All-Ericsson, C., Economou, M.A., Larsson, O., Seregard, S. and Kiessling, R. (2010) Intratumoral Forkhead Box P3-Positive Regulatory T Cells Predict Poor Survival in Cyclooxygenase-2-Positive Uveal Melanoma. Cancer, 116, 2224-2233. https://doi.org/10.1002/cncr.24999

[28] Lee, G.R. (2017) Phenotypic and Functional Properties of Tumor-Infiltrating Regulatory T Cells. Mediators of Inflammation, 2017, Article ID: 5458178. https://doi.org/10.1155/2017/5458178

[29] Assudani, D.P., Horton, R.B.V., Mathieu, M.G., McArdle, S.E.B. and Rees, R.C. (2007) The Role of CD4 ${ }^{+} \mathrm{T}$ Cell Help in Cancer Immunity and the Formulation of Novel Cancer Vaccines. Cancer Immunology, Immunotherapy, 56, 70-80. https://doi.org/10.1007/s00262-006-0154-6

[30] Zou, W. (2006) Regulatory T Cells, Tumour Immunity and Immunotherapy. Nature Reviews Immunology, 6, 295-307. https://doi.org/10.1038/nri1806

[31] Ascierto, P.A. and Marincola, F.M. (2014) What Have We Learned from Cancer Immunotherapy in the Last 3 Years? Journal of Translational Medicine, 12, Article 
No. 141. https://doi.org/10.1186/1479-5876-12-141

[32] Murala, S., Alli, V., Kreisel, D., Gelman, A.E. and Krupnick, A.S. (2010) Current Status of Immunotherapy for the Treatment of Lung Cancer. Journal of Thoracic Disease, 2, 237-244.

[33] Wright, S.E. (2012) Immunotherapy of Breast Cancer. Expert Opinion on Biological Therapy, 12, 479-490. https://doi.org/10.1517/14712598.2012.665445

[34] Shore, N.D. (2015) Advances in the Understanding of Cancer Immunotherapy. BJU International, 116, 321-329. https://doi.org/10.1111/bju.12692

[35] Rosenberg, S.A., Yang, J.C., Sherry, R.M., Kammula, U.S., Hughes, M.S., Phan, G.Q., et al. (2011) Durable Complete Responses in Heavily Pretreated Patients with Metastatic Melanoma Using T-Cell Transfer Immunotherapy. Clinical Cancer Research, 17, 4550-4557. https://doi.org/10.1158/1078-0432.CCR-11-0116

[36] Topalian, S.L., et al. (2012) Safety, Activity, and Immune Correlates of Anti-PD-1 Antibody in Cancer. The New England Journal of Medicine, 366, 2443-2454. https://doi.org/10.1056/NEJMoa1200690

[37] Hodi, F.S., O’Day, S.J., McDermott, D.F., Weber, R.W., Sosman, J.A., Haanen, J.B., Gonzalez, R., Robert, C., Schadendorf, D., Hassel, J.C., et al. (2010) Improved Survival with Ipilimumab in Patients with Metastatic Melanoma. The New England Journal of Medicine, 363, 711-723. https://doi.org/10.1056/NEJMoa1003466

[38] Hamid, O., et al. (2013) Safety and Tumor Responses with Lambrolizumab (Anti-PD-1) in Melanoma. The New England Journal of Medicine, 369, 134-144. https://doi.org/10.1056/NEJMoa1305133

[39] Postow, M.A., et al. (2015) Nivolumab and Ipilimumab versus Ipilimumab in Untreated Melanoma. The New England Journal of Medicine, 372, 2006-2017. https://doi.org/10.1056/NEJMoa1414428

[40] Wolchok, J.D., et al. (2013) Nivolumab plus Ipilimumab in Advanced Melanoma. The New England Journal of Medicine, 369, 122-133. https://doi.org/10.1056/NEJMoa1302369

[41] Le, D.T., et al. (2015) PD-1 Blockade in Tumors with Mismatch-Repair Deficiency. The New England Journal of Medicine, 372, 2509-2520. https://doi.org/10.1056/NEJMoa1500596

[42] Lu, Y.-C., et al. (2014) Efficient Identification of Mutated Cancer Antigens Recognized by T Cells Associated with Durable Tumor Regressions. Clinical Cancer Research, 20, 3401-3410. https://doi.org/10.1158/1078-0432.CCR-14-0433

[43] Lu, Y.-C., et al. (2013) Mutated PPP1R3B Is Recognized by T Cells Used to Treat a Melanoma Patient Who Experienced a Durable Complete Tumor Regression. The Journal of Immunology, 190, 6034-6042. https://doi.org/10.4049/jimmunol.1202830

[44] Abd-El-Rheem, M.S.A. Moist Heat as Immune Therapy for Non Curable Diseases. https://www.researchgate.net/publication/237673914

[45] Robbins, P.F., et al. (2013) Mining Exomic Sequencing Data to Identify Mutated Antigens Recognized by Adoptively Transferred Tumor-Reactive T Cells. Nature Medicine, 19, 747-752. https://doi.org/10.1038/nm.3161

[46] van Rooij, N., et al. (2013) Tumor Exome Analysis Reveals Neoantigen-Specific T-Cell Reactivity in an Ipilimumab-Responsive Melanoma. Journal of Clinical Oncology, 31, e439-e442. https://doi.org/10.1200/JCO.2012.47.7521

[47] Snyder, A., et al. (2014) Genetic Basis for Clinical Response to CTLA-4 Blockade in Melanoma. The New England Journal of Medicine, 371, 2189-2199.

https://doi.org/10.1056/NEJMoa1406498 
[48] Rizvi, N.A., et al. (2015) Mutational Landscape Determines Sensitivity to PD-1 Blockade in Non-Small Cell Lung Cancer. Science, 348, 124-128. https://doi.org/10.1126/science.aaa1348

[49] Lawrence, M.S., et al. (2013) Mutational Heterogeneity in Cancer and the Search for New Cancer-Associated Genes. Nature, 499, 214-218.

https://doi.org/10.1038/nature12213

[50] Vogelstein, B., et al. (2013) Cancer Genome Landscapes. Science, 339, 1546-1558. https://doi.org/10.1126/science.1235122

[51] Tran, E., Robbins, P.F. and Rosenberg, S.A. (2017) "Final Common Pathway" of Human Cancer Immunotherapy: Targeting Random Somatic Mutations. Nature Immunology, 18, 255-262. https://doi.org/10.1038/ni.3682

[52] McGranahan, N., Furness, A.J.S., Rosenthal, R., Ramskov, S., Lyngaa, R., Saini, S.K., et al. (2016) Clonal Neoantigens Elicit T Cell Immunoreactivity and Sensitivity to Immune Checkpoint Blockade. Science, 351, 1463-1469.

https://doi.org/10.1126/science.aaf1490

[53] Jamal-Hanjani, M., Wilson, G.A., McGranahan, N., Birkbak, N.J., Watkins, T.B.K., Veeriah, S., et al. (2017) Tracking the Evolution of Non-Small-Cell Lung Cancer. The New England Journal of Medicine, 376, 2109-2121. https://doi.org/10.1056/NEJMoa1616288

[54] Criscitiello, C. and Curigliano, G. (2013) Immunotherapeutics for Breast Cancer. Current Opinion in Oncology, 25, 602-608. https://doi.org/10.1097/CCO.0000000000000020

[55] Ghochikyan, A., Pichugin, A., Bagaev, A., et al. (2014) Targeting TLR-4 with a Novel Pharmaceutical Grade Plant Derived Agonist, Immunomax ${ }^{\oplus}$, as a Therapeutic Strategy for metastatic breast cancer. Journal of Translational Medicine, 12, Article No. 322. https://doi.org/10.1186/s12967-014-0322-y

[56] Allen, P.B. and Gordon, L.I. (2016) PD-1 Blockade in Hodgkin's Lymphoma: Learning New Tricks from an Old Teacher. Expert Review of Hematology, 9, 939-949. https://doi.org/10.1080/17474086.2016.1235970

[57] Beckermann, K.E., Johnson, D.B. and Sosman, J.A. (2017) PD-1/PD-L1 Blockade in Renal Cell Cancer. Expert Review of Clinical Immunology, 13, 77-84. https://doi.org/10.1080/1744666X.2016.1214575

[58] Beckermann, K.E., Jolly, P.C., Kim, J.Y., Bordeaux, J., Puzanov, I., Rathmell, W.K. and Johnson, D.B. (2017) Clinical and Immunologic Correlates of Response to PD-1 Blockade in a Patient with Metastatic Renal Medullary Carcinoma. Journal for ImmunoTherapy of Cancer, 5, 1.

[59] Garon, E.B. (2015) Current Perspective Sin Immunotherapy for Non-Small Cell Lung Cancer. Seminars in Oncology, 42, S11-S18. https://doi.org/10.1053/j.seminoncol.2015.09.019

[60] Garon, E.B. (2015) Selecting Patients for Immune Checkpoint Inhibition in Lung Cancer. Clinical Advances in Hematology \& Oncology, 13, 490-492.

[61] Robert, C., Schachter, J., Long, G.V., Arance, A., Grob, J.J., Mortier, L., Daud, A., Carlino, M.S., McNeil, C., Lotem, M., et al. (2015) Pembrolizumab versus Ipilimumab in Advanced Melanoma. The New England Journal of Medicine, 372, 2521-2532. https://doi.org/10.1056/NEJMoa1503093

[62] Sonpavde, G. (2017) PD-1 and PD-L1 Inhibitors as Salvage Therapy for Urothelial Carcinoma. The New England Journal of Medicine, 376, 1073-1074.

https://doi.org/10.1056/NEJMe1701182 
[63] Tewari, K.S. and Monk, B.J. (2014) New Strategies in Cervical Cancer: From Angiogenesis Blockade to Immunotherapy. Clinical Cancer Research, 20, 5349-5358. https://doi.org/10.1158/1078-0432.CCR-14-1099

[64] Gaillard, S.L., Secord, A.A. and Monk, B. (2016) The Role of Immune Checkpoint Inhibition in the Treatment of Ovarian Cancer. Gynecologic Oncology Research and Practice, 24, Article No. 11. https://doi.org/10.1186/s40661-016-0033-6

[65] Khanna, S., Thomas, A., Abate-Daga, D., Zhang, J., Morrow, B., Steinberg, S.M., Orlandi, A., Ferroni, P., Schlom, J., Guadagni, F., et al. (2016) Malignant Mesothelioma Effusions are Infiltrated by CD3+ T Cells Highly Expressing PD-L1 and the PD-L1+ Tumor Cells within These Effusions Are Susceptible to ADCC by the Anti-PD-L1 Antibody Avelumab. Journal of Thoracic Oncology, 11, 1993-2005.

[66] Lordick, F., Shitara, K. and Janjigian, Y.Y. (2017) New Agents on the Horizon in Gastric Cancer. Annals of Oncology, 28, 1767-1775.

https://doi.org/10.1093/annonc/mdx051

[67] Pardoll, D.M. (2012) The Blockade of Immune Checkpoints in Cancer Immunotherapy. Nature Reviews Cancer, 12, 252-264. https://doi.org/10.1038/nrc3239

[68] Dolan, D.E. and Gupta, S. (2014) PD-1 Pathway Inhibitors: Changing the Landscape of Cancer Immunotherapy. Cancer Control, 21, 231-237. https://doi.org/10.1177/107327481402100308

[69] Li, Y., Liu, S., Hernandez, J., Vence, L., Hwu, P. and Radvanyi, L. (2010) MART1-Specific Melanoma Tumor-Infiltrating Lymphocytes Maintaining CD28 Expression Have Improved Survival and Expansion Capability Following Antigenic Restimulation in Vitro. The Journal of Immunology, 184, 452-465. https://doi.org/10.4049/jimmunol.0901101

[70] Hoos, A., Ibrahim, R., Korman, A., Abdallah, K., Berman, D., Shahabi, V., et al. (2011) Development of Ipilimumab: Contribution to a New Paradigm for Cancer Immunotherapy. Seminars in Oncology, 37, 533-546. https://doi.org/10.1053/j.seminoncol.2010.09.015

[71] Dudley, M.E., Wunderlich, J.R., Shelton, T.E., Even, J. and Rosenberg, S.A. (2003) Generation of Tumor-Infiltrating Lymphocyte Cultures for Use in Adoptive Transfer Therapy for Melanoma Patients. Journal of Immunotherapy, 26, 332-342. https://doi.org/10.1097/00002371-200307000-00005

[72] Dudley, M.E., Wunderlich, J.R., Yang, J.C., Sherry, R.M., Topalian, S.L., Restifo, N.P., et al. (2005) Adoptive Cell Transfer Therapy Following Non-Myeloablative but Lymphodepleting Chemotherapy for the Treatment of Patients with Refractory Metastatic Melanoma. Journal of Clinical Oncology, 23, 2346-2357. https://doi.org/10.1200/JCO.2005.00.240

[73] Dudley, M.E., Wunderlich, J.R., Robbins, P.F., Yang, J.C., Hwu, P., Schwartzentruber, D.J., et al. (2002) Cancer Regression and Autoimmunity in Patients after Clonal Repopulation with Antitumor Lymphocytes. Science, 298, 850-854. https://doi.org/10.1126/science.1076514

[74] Besser, M.J., Shapira-Frommer, R., Treves, A.J., Zippel, D., Itzhaki, O., Hershkovitz, L., et al. (2010) Clinical Responses in a Phase II Study Using Adoptive Transfer of Short-Term Cultured Tumor Infiltration Lymphocytes in Metastatic Melanoma Patients. Clinical Cancer Research, 16, 2646-2655.

https://doi.org/10.1158/1078-0432.CCR-10-0041

[75] Besser, M.J., Shapira-Frommer, R., Itzhaki, O., Treves, A.J., Zippel, D.B., Levy, D., et al. (2013) Adoptive Transfer of Tumor-Infiltrating Lymphocytes in Patients with Metastatic Melanoma: Intent-to-Treat Analysis and Efficacy after Failure to Prior 
Immunotherapies. Clinical Cancer Research, 19, 4792-4800.

https://doi.org/10.1158/1078-0432.CCR-13-0380

[76] Radvanyi, L.G., Bernatchez, C., Zhang, M., Fox, P.S., Miller, P., Chacon, J., et al. (2012) Specific Lymphocyte Subsets Predict Response to Adoptive Cell Therapy Using Expanded Autologous Tumor-Infiltrating Lymphocytes in Metastatic Melanoma Patients. Clinical Cancer Research, 18, 6758-6770. https://doi.org/10.1158/1078-0432.CCR-12-1177

[77] Pilon-Thomas, S., Kuhn, L., Ellwanger, S., Janssen, W., Royster, E., Marzban, S., et al. (2012) Efficacy of Adoptive Cell Transfer of Tumor-Infiltrating Lymphocytes after Lymphopenia Induction for Metastatic Melanoma. Journal of Immunotherapy, 35, 615-620. https://doi.org/10.1097/CJI.0b013e31826e8f5f

[78] Aoki, Y., Takakuwa, K., Kodama, S., Tanaka, K., Takahashi, M., Tokunaga, A., et al. (1991) Use of Adoptive Transfer of Tumor-Infiltrating Lymphocytes Alone or in Combination with Cisplatin-Containing Chemotherapy in Patients with Epithelial Ovarian Cancer. Cancer Research, 51, 1934-1939.

[79] Rosenberg, S.A., Spiess, P. and Lafreniere, R. (1986) A New Approach to the Adoptive Immunotherapy of Cancer with Tumor-Infiltrating Lymphocytes. Science, 233, 1318-1321. https://doi.org/10.1126/science.3489291

[80] Berenson, J., Einstein, A. and Fefer, A. (1975) Syngeneic Adoptive Immunotherapy and Chemoimmuno-Therapy of a Friend Leukemia: Requirement for T Cells. The Journal of Immunology, 115, 234-238.

[81] Cameron, R.B., Spiess, P.J. and Rosenberg, S.A. (1990) Synergistic Antitumor Activity of Tumor-Infiltrating Lymphocytes, Interleukin-2, and Local Tumor Irradiation.

Journal of Experimental Medicine, 171, 249-263.

https://doi.org/10.1084/jem.171.1.249

[82] North, R. (1982) Cyclophosphamide-Facilitated Adoptive Immunotherapy of an Established Tumor Depends on Elimination of Tumor-Induced Suppressor T Cells. Journal of Experimental Medicine, 55, 1063-1074. https://doi.org/10.1084/jem.155.4.1063

[83] Rosenberg, A.S., Packard, S.B. and Abersold, M.P. (1988) Use of Tumor-Infiltrating Lymphocytes and Interleukin-2 in the Immunotherapy of Patients with Metastatic Melanoma-A Preliminary Report. The New England Journal of Medicine, 319, 1676-1680. https://doi.org/10.1056/NEJM198812223192527

[84] Dudley, M.E., Yang, J.C., Sherry, R., Hughes, M.S., Royal, R., Kammula, U., et al. (2008) Adoptive Cell Therapy for Patients with Metastatic Melanoma: Evaluation of Intensive Myeloablative Chemoradiation Preparative Regimens. Journal of Clinical Oncology, 26, 5233-5239. https://doi.org/10.1200/JCO.2008.16.5449

[85] Linnemann, C., et al. (2015) High-Throughput Epitope Discovery Reveals Frequent Recognition of Neo-Antigens by CD4+ T Cells in Human Melanoma. Nature Medicine, 21, 81-85. https://doi.org/10.1038/nm.3773

[86] Rajasagi, M., et al. (2014) Systematic Identification of Personal Tumor-Specific Neoantigens in Chronic Lymphocytic Leukemia. Blood, 124, 453-462.

https://doi.org/10.1182/blood-2014-04-567933

[87] Rizvi, N.A., et al. (2015) Cancer Immunology. Mutational Landscape Determines Sensitivity to PD-1 Blockade in Non-Small Cell Lung Cancer. Science, 348, 124-128. https://doi.org/10.1126/science.aaa1348

[88] Tran, E., et al. (2014) Cancer Immunotherapy Based on Mutation-Specific CD4+ T Cells in a Patient with Epithelial Cancer. Science, 344, 641-645.

https://doi.org/10.1126/science.1251102 
[89] Tran, E., Ahmadzadeh, M., Lu, Y.C., et al. (2015) Immunogenicity of Somatic Mutations in Human Gastrointestinal Cancers. Science, 350, 1387-1390.

https://doi.org/10.1126/science.aad1253

[90] Rosenberg, S.A., Goff, S.L., Feldman, S.A., Zacharakis, N., et al. (2018) Immune Recognition of Somatic Mutations Leading to Complete Durable Regression in $\mathrm{Me}$ tastatic Breast Cancer. Nature Medicine, 24, 724-730.

https://doi.org/10.1038/s41591-018-0040-8

[91] Sewell, A.K., Crowther, M.D., Dolton, G., Legut, M., et al. (2020) Genome-Wide CRISPR-Cas9 Screening Reveals Ubiquitous T Cell Cancer Targeting via the Monomorphic MHC Class I-Related Protein MR1. Nature Immunology, 21, 178-185. https://doi.org/10.1038/s41590-019-0578-8

[92] Abd-El-Rheem, M.S.A. (1997) The Use of Moist Heat as Immuno Stimulant in Definitive Treatment of Cutaneous Cancer and Other Affections. The Alexandria Journal of Veterinary Sciences, 13, 533-538. 